\title{
Ensino de Design Instrucional: Relatos de Experiência
}

\author{
Cátia Luzia Oliveira da Silva ${ }^{1}$, Luciana de $\operatorname{Lima}^{1}$, Robson Carlos Loureiro ${ }^{1}$, \\ Alberto de Oliveira Jucá ${ }^{1}$ \\ ${ }^{1}$ Instituto UFC Virtual - Universidade Federal do Ceará (UFC) - Campus do Pici \\ Bloco 901, 1 o andar, CEP: 60.440-554 - Fortaleza, CE - Brazil \\ \{catia, luciana, robson\}@virtual.ufc.br, redfox19111@gmail.com
}

\begin{abstract}
This article describes a teaching experience in two Instructional Design classes at a Brazilian public university. The activities reported here offered students a concrete experience of the ADDIE Instructional Design Model (analysis, design, development, implementation and evaluation), providing them a practical experience of the theory, through the direct contact with real clients.
\end{abstract}

Resumo. Este artigo descreve experiência de ensino em duas turmas de Design Instrucional de universidade pública brasileira. As atividades aqui relatadas ofereceram aos alunos uma vivência concreta do modelo de Design Instrucional ADDIE (análise, design, desenvolvimento, implementação e avaliação), propiciando uma experiência prática da teoria, a partir do contato direto com clientes reais.

\section{Introdução}

As atividades de Design Instrucional focam no processo de aprendizagem - intencional e significativo. Fundamentada em diversas outras áreas do saber, o Design Instrucional pode ser definido como "a ciência e a arte de criar especificações detalhadas para o desenvolvimento, avaliação e manutenção de situações que facilitam a aprendizagem e a performance". (Richey, Klein \& Tracey, 2011, p. 3) É um processo sistêmico, apoiado nos conhecimentos sobre a aprendizagem humana e apresenta fases cujo alcance tanto pode ser mais imediato quanto mais longo. (Gagné, Wager, Golas \& Keller, 2005)

De um modo geral, modelos de Design Instrucional aplicam conceitos sistemáticos de análise, planejamento, desenvolvimento, implementação e avaliação, dentro de um processo iterativo de planejamento de oportunidades de aprendizagem. Em tal processo, cada componente (aluno, professor, materiais, ambiente de aprendizagem) é crucial para que a aprendizagem ocorra com sucesso. Vantagens da abordagem sistêmica traduzem-se no papel do aprendiz como sujeito, o favorecimento da ação coordenada entre designers, desenvolvedores e demais atores, além da congruência entre objetivos, atividades e avaliação. Sendo assim, no Design Instrucional é importante ressaltar a necessidade da compreensão de construções educativas que envolvam a complexidade e a síntese com a finalidade de se encontrar meios e recursos para cumprir os objetivos previamente traçados. (Ramos, Santos, 2006)

O design instrucional também é uma área de atuação profissional. Designers instrucionais devem ser versados em várias áreas do saber (tecnologia, pedagogia, 
comunicação, psicologia, negócios, etc.) para que saibam planejar episódios de aprendizagem intencional sistematicamente. Eles devem estar atentos a aspectos socioculturais da aprendizagem para que façam escolhas que gerem as melhores oportunidades educacionais possíveis.

A disciplina de Design Instrucional, contudo, necessita ser uma área de estudo consolidada em nossas universidades. Embora seja um campo desenvolvido e prestigiado na comunidade científica em países da América do Norte e da Europa, por exemplo, carece de tradição no Brasil, onde infelizmente figura como área do conhecimento praticamente desconhecida.

Este artigo relata uma experiência de ensino com duas turmas de uma disciplina de Design Instrucional em universidade pública brasileira, mais especificamente em curso de bacharelado em Sistemas e Mídias Digitais. Particularmente para este curso, o Design Instrucional é uma área de estudo de grande importância, tendo em vista que seus alunos egressos atuarão também como profissionais no desenvolvimento de produtos educacionais. Sendo assim, essa disciplina complementa a formação básica do aluno para a compreensão de quais conteúdos e de que forma as mídias e os sistemas digitais podem ser utilizados no âmbito educacional para aprimorar a aprendizagem. Para atingir tal fim, a disciplina procura oferecer fundamentação teórica suficiente sobre como ocorre a aprendizagem, em diferentes perspectivas educacionais, pois é tal fundamentação que guia a prática de qualquer profissional de design instrucional, oferecendo insumos para uma atuação crítica e reflexiva, e não somente técnica.

As atividades realizadas ao longo do semestre propunham-se a oferecer uma vivência concreta do modelo clássico e didático de Design Instrucional adotado - o modelo ADDIE de análise, design, desenvolvimento, implementação e avaliação propiciando uma experiência prática da teoria.

\section{A disciplina de Design Instrucional}

A disciplina de Design Instrucional (DI) é ofertada como obrigatória no $4^{\circ}$ semestre do curso de Sistemas e Mídias Digitais por Universidade Pública Brasileira. No semestre 2012.1 foi ofertada no período da tarde, $4^{\mathrm{a}}$ feira e $6^{\mathrm{a}}$ feira, com a formação de duas turmas (cada uma com seu respectivo docente), totalizando 64 horas/aula. Na turma A se matricularam vinte e seis alunos; destes, dois alunos trancaram a matrícula e três necessitaram terminar a disciplina antes do período proposto. Na turma B havia quinze alunos matriculados; desses, treze obtiveram aprovação.

Os alunos tiveram a oportunidade de vivenciar uma experiência concreta, em ambas as turmas, ao desenvolver projetos que atendessem às necessidades de clientes reais, visando ao desenvolvimento do design instrucional de cursos, disciplinas ou aulas. O programa da disciplina em questão, atualmente, visa a introduzir o aluno no campo primordialmente prático do Design Instrucional, permitindo-lhe conhecer uma abordagem sistêmica, enquanto desenvolve oportunidades intencionais de aprendizagem. A disciplina também permite ao aluno praticar conceitos de análise, planejamento, desenvolvimento, implementação e avaliação (modelo ADDIE) da instrução no contexto educacional vinculado ao uso das tecnologias digitais.

Diante de uma proposta de estudos práticos sobre Design Instrucional, a disciplina apresenta como objetivos: 
- Compreender o trabalho do profissional Designer Instrucional e suas vinculações ao mercado de trabalho e ao trabalho acadêmico;

- Compreender os aspectos teóricos vinculados às teorias de aprendizagem aplicadas ao contexto do Design Instrucional;

- Planejar, coletar e analisar dados de contextos práticos para o desenvolvimento de matriz de unidade de aprendizagem;

- Desenvolver relatórios de coleta de dados para a concretização de Análise Contextual;

- Desenvolver roteiro de propostas de design instrucional que atenda a objetivos previamente estabelecidos;

- Desenvolver um plano de implementação de uma proposta de Design Instrucional;

- Conhecer meios de avaliação em Design Instrucional.

$\mathrm{Na}$ turma A, foram ministradas doze aulas com discussões teóricas e apresentação de palestras que embasam o conceito de Design Instrucional. Apesar de seu caráter prático, houve a necessidade dessa introdução teórica para a familiarização dos alunos com os conceitos básicos sobre DI e com o contexto do profissional dessa área do conhecimento. Para que pudessem compreender na prática o trabalho do designer instrucional, os alunos vivenciaram situações reais a partir da vinculação a clientes convidados pelos professores da disciplina apresentando características e necessidades específicas. Os alunos puderam, assim, estudar e elaborar propostas de solução aos problemas apresentados por esses clientes pautando-se no modelo ADDIE (Análise, Design, Desenvolvimento, Implementação e Avaliação).

Foram convidados quatro clientes, em geral, professores da mesma Universidade Pública dos alunos, vinculados a disciplinas presenciais ou semipresenciais ou à coordenação de cursos de extensão. O professor 1, vinculado à disciplina de Narrativas Multimídia do curso presencial de Sistemas e Mídias Digitais apresentou como necessidade básica, a utilização de espaço na internet para armazenamento e compartilhamento de materiais didáticos utilizados em sua disciplina; solicitou ainda sugestões de design para apresentação de seus conteúdos específicos. O professor 2 , vinculado à disciplina de Cálculo Diferencial e Integral I do curso semipresencial de Licenciatura em Matemática solicitou a utilização de uma abordagem diferenciada da tradicional, comumente utilizada na disciplina, diante de inovações metodológicas e de design. O material didático da disciplina é utilizado desde 2006 e até o presente momento não sofreu alterações.

O professor 3, vinculado ao curso semipresencial de Formação para a Docência Integrada às TIC (DTIC) destinada à formação dos docentes da referida Universidade, solicitou a alteração da proposta metodológica do curso, bem como modificação na estruturação do material didático utilizado em duas edições anteriores realizadas nos semestres de 2011.1 e 2012.1. O professor 4, vinculado ao curso de extensão semipresencial Cidade e Megaeventos Esportivos destinado à preparação dos cidadãos que residem nas cidades contempladas com estádios desportivos recém-construídos ou restaurados voltados para os jogos de futebol da Copa do Mundo de 2014, solicitou um design a ser utilizado e implementado desde sua origem, considerando-se que se trata de 
um curso novo, sem edições anteriores.

As demais aulas foram destinadas para a Análise Contextual visando à compreensão mais profunda das necessidades de cada cliente, o Desenvolvimento de Unidades de Aprendizagem diante da construção da matriz de design instrucional, Desenvolvimento de Roteiros e/ou Storyboards, e, a preparação da proposta final para apresentação aos clientes. Os alunos foram, então, subdivididos em seis grupos. Para atender aos professores da disciplina de Narrativas Multimídia e do curso de extensão Cidade e Megaeventos, foram destinados dois grupos, um para cada professor. No caso da disciplina de Cálculo Diferencial e Integral I e do curso DTIC, foram destinados quatro grupos, dois para cada professor.

Os alunos foram avaliados de forma processual e gradativa, conforme a aplicação do modelo ADDIE era implementada. Foram pontuados o planejamento da análise contextual, o relatório da análise contextual, a matriz de design instrucional, os roteiros e/ou storyboards desenvolvidos e a proposta final apresentada aos clientes. Os instrumentos utilizados pelos alunos foram todos pautados no uso das ferramentas digitais vinculadas à web 2.0. Os arquivos de texto, as planilhas eletrônicas, bem como os desenhos e layouts relativos à construção de cada etapa do desenvolvimento do design instrucional foram compartilhados entre os integrantes de cada grupo e os professores da disciplina de DI, analisados e discutidos no momento da aula presencial e momentos posteriores, à distância.

A turma B da disciplina de Design Instrucional também sentiu a necessidade de oferecer ampla fundamentação teórica aliada à prática. Sistemática semelhante à Turma A foi utilizada, havendo pequenas modificações, de acordo com as características e interesses dos alunos. Por exemplo, uso de blogs individuais dos alunos foi encorajado ao longo da disciplina, para que cada um enviasse as atividades propostas (fichamentos, pesquisas, mapas mentais, reflexões, etc.). Houve uma palestra sobre o trabalho do designer instrucional, proferida por convidado atuante no mercado americano, por meio de videoconferência. Os alunos puderam participar deste momento, formulando várias perguntas que variaram desde questões relativas a mercado de trabalho e competências específicas do profissional de design instrucional até questões sobre pesquisa acadêmica na área. O palestrante também teve a oportunidade de demonstrar exemplos de trabalhos de sua autoria, desenvolvidos segundo diferentes perspectivas pedagógicas, desde a mais tradicional até a mais construtivista.

Também, clientes em potencial fizeram apresentações no início do semestre, enfocando algumas das necessidades instrucionais de seus locais de trabalho. Tais clientes constituíram-se de profissionais atuantes em setores específicos de uma unidade da mesma universidade onde os alunos estudam, cuja missão é "atuar nas modalidades de educação presencial e a distância utilizando e desenvolvendo soluções tecnológicas e metodológicas com a finalidade de garantir a qualidade e inovação do processo de ensino e aprendizagem por meio de múltiplas linguagens e tecnologias." Os setores são descritos a seguir: 1) Setor de audiovisual: estúdio responsável pela produção de conteúdo didático audiovisual para aulas de cursos vinculados à Universidade Aberta do Brasil (UAB). Este cliente apresentou um leque de necessidades, que variavam desde diversificar o formato pedagógico dos vídeos produzidos pelo setor até a própria atitude dos professores em relação ao meio audiovisual como insumo de suas aulas semipresenciais; 2) Centro de Produção I: setor que produz conteúdos para web para os 
cursos da UAB, através de processo de Transição Didática, compreendendo desde o planejamento de aulas até a disponibilização do conteúdo em determinada mídia ou tecnologia. Este cliente possui um processo próprio de design instrucional para o desenvolvimento de seu material pedagógico. (Pequeno et al, 2011) Entretanto, devido ao ritmo acelerado de trabalho desse setor e aos prazos exíguos, às vezes fica impossibilitado de realizar algumas atualizações em seus materiais de aula em tempo hábil; 3) Setor de Suporte: setor responsável pelo suporte e manutenção de toda a infraestrutura de equipamentos e rede de comunicação da unidade em questão. Este setor também se ocupa por gerir as ferramentas de videoconferência utilizadas nos cursos semipresenciais da UAB. Este cliente observa que há pouco proveito, por parte dos alunos, dos momentos em que a videoconferência é utilizada.

A turma B dividiu-se espontaneamente em quatro equipes e cada equipe escolheu um cliente que se afinasse com seus interesses, focando problemas instrucionais. A partir de então, da mesma forma como ocorreu na turma A, as equipes foram usando os conhecimentos adquiridos ao longo do semestre para aplicá-los no trabalho com seus respectivos clientes, passando pelas fases do modelo ADDIE. A forma de avaliação também foi se dando continuamente, à medida que as equipes avançavam nas etapas sucessivas de atividades. Cada momento do processo foi sendo documentado através de relatórios escritos que serviram também de avaliação das equipes. Momentos de "consultoria" foram prestados por parte da docente responsável a fim de tirar dúvidas e ajustar possíveis falhas nos trabalhos. Outras atividades, tais como a criação de tutoriais educacionais multimídia resultaram proveitosas aos alunos, que puderam criar tutoriais vinculados às necessidades específicas de seus clientes.

Ao final do semestre, como trabalho de conclusão, as equipes prepararam um kit para seus respectivos clientes, contendo: 1) Material didático, constituído de um roteiro do material proposto, acrescido de um tutorial multimídia; 2) Relatório impresso e digital (documentação) da proposta de Design Instrucional. As equipes também fizeram uma defesa oral de suas propostas, apresentando seus materiais aos clientes, que foram convidados a conferir parte da nota deste trabalho final, referente ao seu grau de satisfação com a proposta apresentada, preenchendo um instrumento de avaliação.

\section{Metodologia}

Diante de uma proposta de pesquisa qualitativa, o planejamento, a coleta de dados e a análise dos resultados obtidos estão pautados em uma concepção interpretativa do discurso de alunos, professores e clientes atuantes como sujeitos centrais na compreensão da importância do Design Instrucional para o curso de Sistemas e Mídias Digitais, bem como os entraves a serem superados. A teorização é atingida pelo próprio leitor por meio da imersão no contexto apresentado (Stake, 1998).

A coleta de dados se baseia, portanto, em dois instrumentos: observação participante e entrevista semiestruturada. As observações ocorreram durante as aulas do semestre e foram registradas pelas professoras das turmas A e B em arquivos de texto com ênfase na compreensão que os alunos desenvolviam sobre o conceito e a aplicabilidade do Design Instrucional, bem como, nas dificuldades vivenciadas nesse processo. As entrevistas foram realizadas com apenas dois sujeitos ao final do semestre letivo: um aluno da disciplina de DI e um professor que se apresentou como um dos clientes.

Sendo assim, para o relato que se apresenta, o público alvo se compõe por trinta 
e seis alunos e um professor. Em geral, os alunos apresentam faixa etária média de 21 anos, com experiência de navegação em internet, busca de informações na web, participação em redes sociais, além de hábitos de estudo noturnos devido ao fato de o curso oferecer suas disciplinas no período da tarde. O professor que se apresentou como cliente, com idade de 51 anos, atua na docência há trinta anos, com experiência na educação básica e superior. Com conhecimento no uso das tecnologias digitais na docência, mestrado e doutorado na área da Educação, atua em projetos governamentais para o incentivo da inserção desse tipo de tecnologia na educação desde a década de 1980.

Os dados coletados são analisados a partir da interpretação direta das anotações realizadas em sala de aula e dos textos transcritos das entrevistas concretizadas com aluno e professor. Os resultados obtidos com as duas turmas são então comparados para que os elementos convergentes e divergentes entre ambas sejam evidenciados.

\section{Resultados Obtidos}

$\mathrm{Na}$ turma A, para solucionar os problemas propostos pelo professor 1 vinculado à disciplina de Narrativas e Multimídia, o grupo responsável optou por buscar e sugerir um ambiente virtual de aprendizagem específico para o desenvolvimento de histórias e narrativas denominado Movellas; apresentaram sugestões metodológicas de abordagem do conteúdo em sala de aula, além de proposta de material didático para se trabalhar o conteúdo da disciplina de forma presencial e a distância.

Para a disciplina de Cálculo Diferencial e Integral I relacionada ao professor 2, o primeiro grupo apresentou um design diferenciado para a apresentação do conteúdo, além do uso de mapas conceituais interativos e vídeos para a construção do conhecimento durante o período vigente da disciplina no ambiente virtual de aprendizagem comumente utilizado como ponto de encontro virtual entre os alunos da disciplina. O segundo grupo não conseguiu atingir o objetivo proposto devido ao fato de seus integrantes necessitarem viajar pelo Projeto Ciência sem Fronteiras antes do término da disciplina.

No caso do curso DTIC vinculado ao professor 3, o primeiro grupo propôs alterações no material didático desenvolvido, principalmente na inclusão de explicações passo a passo de como utilizar as ferramentas abordadas no curso; optaram por utilizar ferramentas da web 2.0 como proposta de interação entre os cursistas. O segundo grupo apresentou uma proposta pautada no modelo utilizado nos cursos semipresenciais da referida Universidade modificando apenas a estrutura do material didático, já implementada pelo cliente.

Em relação ao curso de extensão Cidade e Megaeventos Esportivos referente ao professor 4, o grupo responsável propôs estrutura, metodologia e design pautados no ambiente virtual de aprendizagem Moodle atendendo a necessidade do cliente que buscou por espaços de comunicação síncrona e assíncrona a distância, assim como pela disponibilização de textos variados a serem estudados pelos cursistas.

Já na turma B, a equipe que trabalhou juntamente com o Setor de Audiovisual, formulou uma proposta de curso de oratória para os professores da UAB que gravam vídeos instrucionais como parte de suas atividades cotidianas e que precisam aprimorar qualitativamente seu desempenho frente às câmeras. Segundo dados da etapa de análise, esta se configurava, na ocasião, como a necessidade mais premente por parte dos 
professores.

Duas equipes optaram pelo trabalho com o Centro de Produção I para reformulação de conteúdos de aulas veiculadas via web dos cursos semipresenciais de Educação Infantil da UAB. Uma vez que as aulas já estavam no ar há certo tempo, elas careciam de aprimoramento. As equipes sugeriram não só reformulações na sequência didática das aulas, mas também a inclusão de diferentes mídias para veicular o conteúdo trabalhado. Uma das equipes chegou a propor uma interface nova para a veiculação das aulas web, tornando-a mais simples, mais intuitiva e interativa. Já outra equipe propôs a utilização de agente virtual para interagir com os alunos durante as aulas.

Por fim, a equipe que escolheu atuar juntamente com o Setor de Suporte formulou proposta de curso sobre o uso pedagógico de videoconferências para tratar a falta de preparo, de um modo geral, de professores que usam ferramentas de videoconferência para interagir com seus alunos espalhados pelos diversos polos da UAB. Além de proposta de uma unidade didática para curso a distância sobre o tema, a equipe também criou um vídeo sobre boas práticas em videoconferências, tratando o assunto de forma leve e descontraída.

Todas as equipes da turma $\mathrm{B}$ formularam um relatório (impresso e digital) ao final de suas respectivas atividades, que foi compartilhado com os clientes durante a apresentação oral. Tal relatório explicitou, para cada proposta em particular, itens tais como: contextualização do problema, análise de performance, modelo de design instrucional utilizado, público alvo, lista de objetivos instrucionais, recursos necessários, opções de modos de oferta, estimativas de custos para cada opção de oferta, inventário de tarefas, lista de objetivos de performance, métodos de avaliação, conjunto de estratégias instrucionais, mídias sugeridas e/ou a serem desenvolvidas, guias didáticos para o aluno e para o professor e, finalmente, roteiro finalizado de pelo menos uma unidade didática.

Observou-se que, tanto na turma A quanto na turma B, as atividades práticas, aliadas ao contexto teórico contribuíram para que os alunos compreendessem uma parte da proposta de trabalho do designer instrucional. Foi possível vivenciar apenas as etapas iniciais do modelo ADDIE, devido ao tempo curto de apenas um semestre letivo e à complexidade do trabalho do DI. As etapas de desenvolvimento, implementação e avaliação poderiam ser estudadas com maior profundidade em outro momento, diante da abertura de uma nova disciplina com caráter de continuação desta primeira.

O fato de se trabalhar com situações-problema reais diante das necessidades de cada cliente, aliado à utilização das tecnologias digitais vinculadas às ferramentas da web 2.0 contribuiu para a imersão dos alunos na busca de informações sobre o cliente, sobre suas necessidades, e, principalmente, na elaboração de propostas de solução aos problemas apresentados de forma viável e exequível.

\section{Depoimento do cliente - disciplina de Narrativas e Multimídia}

A perspectiva docente que se emprega na aula de Narrativas e Multimídia é pautada pela busca de interação e de consolidação de novos caminhos para o processo de ensino, aprendizagem e avaliação. Ao se ter o contato com os alunos de DI esta característica ficou evidenciada. Os alunos questionaram o sentido de se buscar essa mudança constante em razão das necessidades da sociedade da informação. A proposta dos alunos convergiu com as necessidades docentes. Suas ideias apresentaram novas perspectivas 
que não haviam sido percebidas. A pesquisa e a descoberta de um software dentro das redes sociais com a finalidade de construção de narrativas é um exemplo do engajamento dos alunos para solucionar os problemas apresentados pelo professor enquanto cliente. Elementos desta solução serão implementados no semestre letivo 2013.2 e as expectativas são positivas.

Durante a apresentação da proposta final, os alunos sugeriram inovações metodológicas pautadas pela sua prática discente, fundamentando caminhos didáticos e métodos que seriam mais interessantes para garantir a integração entre docente e discente. A partir dessa sugestão o professor resolveu remodelar e replanejar as aulas da disciplina. Uma organização mais clara dos textos que serão utilizados com os alunos, integrados com ambientes nas redes sociais possibilitam uma discussão extracurricular com ampliação da ação docente fora da sala de aula. Este espaço também proporciona ao discente sugerir links e arquivos que podem auxiliar em outras compreensões e diversidades em relação ao conteúdo trabalhado.

A objetividade e a clareza nas ideias foram determinantes para a compreensão do professor sobre a proposta apresentada. Isso possibilitou a realização de um diálogo entre docente e discentes com a finalidade de equalizar as novas ideias com o que já era desenvolvido na disciplina. Dessa forma, consolida-se um passo para a docência participativa na qual o professor deixa de trabalhar de forma isolada para construir os conteúdos e abordagens juntamente com os discentes. Essa prática docente se harmoniza com as exigências da sociedade contemporânea em que os fenômenos, dada sua diversidade, necessitam de olhares diferentes para a melhoria da sua compreensão.

Considera-se que uma das limitações foi a formação em meios tradicionais dos discentes e a falta de integração com outras disciplinas do curso. Esse aspecto gerou certo receio nos alunos para apresentação de propostas mais ousadas em termos de experimentação metodológica, já que o professor, enquanto cliente, havia se colocado aberto a ações transformadoras da docência. A necessidade do docente possibilitaria a quebra de paradigmas tradicionais do ensino, aprendizagem e avaliação. Entretanto, os alunos apresentaram propostas ainda vinculadas à representação da hierarquia na relação docente e discente já consolidada.

Analisando-se a exequibilidade das ideias propostas baseadas nas ferramentas da web 2.0, a fundamentação das sugestões metodológicas, o trabalho cooperativo entre os alunos e o professor, o produto construído foi bem recebido pelo cliente que externou satisfação e indícios claros de uso das ideias apresentadas. Dessa forma, acredita-se que as disciplinas com este tipo de abordagem devem ser estimuladas, aumentando o engajamento e o significado para discentes e docentes no estabelecimento de parcerias com a finalidade de construção de conteúdos e métodos pautados pela relação que se forma entre teoria e prática.

\section{Depoimento de um aluno - disciplina de Design Instrucional}

A disciplina de Design Instrucional (DI) foi ministrada de forma esquematizada, em que os alunos foram informados sobre os objetivos da disciplina e em que consistia seu trabalho final. Para tanto, foi estimulado o uso de conhecimentos pré-existentes visando com que o processo de aprendizagem se desse por meio de um sistema cíclico de informação, execução e avaliação, no qual a retenção dos conceitos e aplicações do DI se desse de forma permanente. 
Destacou-se o estímulo a uma autonomia do aluno, com a construção de um grupo fechado dentro da comunidade virtual do Facebook, no qual se buscou reconhecer as necessidades do grupo de alunos, fornecer informações, definir estratégias de estudo, conduzir atividades e, principalmente, acompanhar o desenvolvimento da proposta dos trabalhos finais. Também tendo como ideia dar suporte à elaboração do trabalho final, cada participante da disciplina construiu um blog dedicado à temática abordada. $\mathrm{O}$ conjunto de blogs se revelou de estrema valia na forma de material de consulta rápida, já que os mesmos, em sua maioria, apresentavam os conteúdos estudados de forma resumida e com detalhes particulares de entendimento de cada participante.

As fases do DI foram apresentadas de forma aplicada, em que a cada aula ou grupo de aulas, as etapas fossem passadas de forma independente, e com um exercício de aplicação prática do conteúdo trabalhado. Dessa forma, foram estudados: 1) por meio da identificação das necessidades, identificação de objetivos, caracterização dos usuários - a análise do DI; 2) com o planejamento da instrução e produção de processos a serem aplicados - o design e desenvolvimento do DI; 3) da aplicação proposta relacionada ao problema tratado - a implementação do DI. Destaca-se que a fase avaliação do DI se verificou de forma parcial, dado o fato que apenas foi avaliada as ideias contidas nas propostas no projeto, sem que houvesse um acompanhamento dos resultados alcançados pelo cliente de forma prática. No particular ao trabalho feito em equipe, a elaboração de uma proposta de DI foi, sem dúvida, um dos elementos mais válidos da disciplina. A superação de cada etapa, dentro do modelo escolhido, fez com que o mesmo fornecesse aos participantes a real dimensão dos desafios envolvidos, o desenvolvimento de habilidades de construção de soluções frente aos problemas identificados, bem como fez com que o conteúdo teórico tivesse seu valor e necessidade reconhecidos.

Fundamental destacar que ao se trabalhar o DI por meio de uma aplicação prática, vinculada a um problema real de um cliente que, ao final do processo, viria a julgar as propostas do projeto apresentado, foi de extrema valia na construção efetiva da relação entre o caráter teórico e potencial prática dos processos relacionados ao DI. A cada desafio encontrado, os alunos foram lançados num processo de busca de novas informações, por meio de debates e leituras, visando à solução e superação do mesmo. Esse contínuo processo, que envolveu tanto os alunos quanto o cliente e a professora, fez com que ocorresse uma contínua troca de ideias que facilitaram os ajustes necessários durante a construção da proposta de DI a ser apresentada. Ponto a ser destacado, os diferentes estágios de formação dos membros da equipe, do graduando sem experiência profissional até o graduado com experiência no exterior, criou uma ampla visão dos desafios, o que em muito contribuiu para as soluções propostas.

Resta, por fim, registrar uma sugestão que visa a contribuir no melhoramento da disciplina de Design Instrucional. Em uma avaliação informal em que os participantes da nossa proposta fizeram após a apresentação da proposta ao cliente, e consequente finalização da disciplina, pensamos ser válido e mais significativo, que os projetos apresentados versassem sobre o mesmo problema/cliente. Assim, a nosso ver, ficaria mais fácil identificar e comparar as melhores ideias e soluções relacionadas a um único problema apresentado. Bem como, o cliente, poderia dar um retorno mais satisfatório em relação à proposta que melhor fosse aplicada dentro da sua realidade prática. 


\section{Considerações Finais}

Este artigo tratou de um relato de experiência no ensino de Design Instrucional, disciplina importante para a formação de todo profissional que irá planejar materiais didáticos para qualquer modalidade educacional, seja ela presencial, a distância ou semipresencial. O relato aqui apresentado oferece uma perspectiva de ensino situada em contexto real, a partir do trabalho com clientes concretos. A experiência descrita resultou vantajosa para a aprendizagem dos alunos envolvidos, que puderam vivenciar na prática a teoria estudada ao longo do semestre letivo.

Entretanto, ensinar Design Instrucional em nosso País oferece desafios. O mais flagrante é a falta de material abundante em língua portuguesa, o que demanda do docente trabalho extra de pesquisa. Outro desafio é a falta de um mercado de trabalho consolidado na área, especialmente na região onde se deu a experiência ora descrita. Isto impacta negativamente o ensino de alguns conteúdos relacionados à questão econômica, tais como: custos, retorno sobre investimento, entre outros.

Ainda assim, é preciso ultrapassar as dificuldades e ensejar oportunidades diferenciadas de ensino em Design Instrucional. Compartilhar as experiências nesse campo do saber também se faz necessário, pois isso fará com que o Design Instrucional torne-se cada vez mais como área de estudo consolidada em nossas universidades, especialmente diante da necessidade da inclusão de $20 \%$ da carga horária a distância.

\section{Referências}

Filatro, A. (2003) Design Instrucional Contextualizado: Educação e Tecnologia. Editora Senac, São Paulo, $3^{\mathrm{a}}$ edição.

Filatro, A. (2008) Design Instrucional na Prática. Pearson - Prentice Hall, São Paulo.

Gagné, R. M., Wager, W. W., Golas, K. C. e Keller, J. M. Principles of Instrucional Design. (2005) Belmont: Thomson, $5^{\text {a }}$ edição.

Pequeno, H. S. L.; Loureiro, R. C.; Pequeno, P. A. L.; Barone, N. M.; Vasconcelos, F. H. L.; Sarmento, W. W. F.; Pequeno, M. C. (2011) Avaliação de Conteúdos Educacionais Digitais: o modelo do Instituto UFC Virtual. In: 22o. Simpósio Brasileiro de Informática na Educação e o 17o. Workshop de Informática na Escola, 2011, Aracaju. Anais do 22o. Simpósio Brasileiro de Informática na Educação e o 17o. Workshop de Informática na Escola Workshop de Informática na Escola. Aracaju: SBIE.

Ramos, A. F.; Santos, P. K. dos. (2006) A contribuição do Design Instrucional e das Dimensões da Educação para o desenvolvimento de Objetos de Aprendizagem. In: 12o. Workshop de Informática na Escola, 2006, Campo Grande. Anais do 120. Workshop de Informática na Escola. Campo Grande: WIE.

Richey, R. C., Klein, J. D., Tracey, M. W. (2011) The Instructional Design Knowledge Base - Theory, Research and Practice. Routledge, NY.

Smith, P. L. e Ragan, T. J. (2005) Instructional design. Wiley/Jossey-Bass, $2^{a}$ edição.

Stake, R. E. Investigación con Estudio de casos. (1998) Morata, Madrid. 